\title{
Uma experiência interdisciplinar de psicanalistas com profissionais da saúde
}

\author{
An inter-disciplinary experiment with health professionals carried out by \\ psychoanalysts
}

\section{Introdução}

Cecilia Luiza Montag Hirchzon ${ }^{1}$ Heloisa Helena Sitrângulo Ditolvo²

Alguns setores profissionais, como os dos paramédicos (fisioterapeutas, fonoaudiólogos, terapeutas ocupacionais, nutricionistas, enfermeiros, assistentes sociais) e certas especialidades médicas que envolvem a intersubjetividade, freqüentemente carecem de formação e experiências que propiciem a percepção de aspectos psíquicos e emocionais nas relações com seus pacientes.

Recentemente psicanalistas de diferentes escolas têm convergido na concepção de que a mente humana é mais interativa do que monádica. Nesse sentido,
a necessidade de reconhecimento envolve este paradoxo fundamental: no exato momento de realizar a nossa própria vontade independente, somos dependentes de um outro que a reconheça. No exato momento em que chegamos a compreender o significado do eu, do meu, somos forçados a ver as limitações deste 'self'. No momento em que entendemos que mentes separadas podem partilhar sentimentos semelhantes, começamos a achar que essas mentes podem discordar. (Benjamin, 1990, p.190) (tradução nossa)

Enquanto pacientes, as pessoas não esperam dos profissionais da saúde somente soluções para seus problemas, mas também buscam receptividade e acolhimento. Assim como seus pacientes, os diversos profissionais também têm de ser cuidados. Além de constituir um modelo de comportamento a ser seguido, aprendemos com Leonardo Boff (1999, p.92) que "o cuidado é mais do que um ato singular ou uma virtude ao lado das outras. É um modo de ser, isto é, é a forma como a pessoa humana se estrutura e se realiza no mundo com os outros".

Um grupo pode ter a função de dar suporte ao profissional que cuida. O trabalho em equipe dá respaldo aos profissionais que podem compartilhar suas dúvidas, impotências e fracassos, assim como participar de suas vitórias. O aprender se dá a partir da vivência dos profissionais no próprio grupo, no qual experienciam situações de receptividade às suas necessidades.

\footnotetext{
${ }^{1}$ Departamento de Psicanálise do Instituto Sedes Sapientae; Colaboradora da Comissão de Divulgação e Cursos da Sociedade Brasileira de Psicanálise de São Paulo/SBPSP. <cecilu@bol.com.br>

${ }^{2}$ Colaboradora da Comissão de Divulgação e Cursos da SBPSP. <heloisaditolvo@sbpsp.org.br>

${ }^{1}$ Rua Carlos Sampaio, 158

Paraíso - São Paulo, SP

01.333-020
} 


\section{ESPAÇO ABERTO}

Uma regra de ouro, como recomenda Pichon Rivière (1983) no manejo das reuniões, é trabalhar e operar sobre a informação emergente, aquela que o grupo "atualiza em cada momento e que corresponde ao que momentaneamente pode admitir e elaborar. Sem ansiedade não se aprende, e com muita, tão pouco" (Bleger, 1972, p.74) (tradução nossa).

A ciência do século $X X$ progrediu principalmente na direção da especialização, avaliando-se seu rigor pelo aprofundamento cada vez maior do seu objeto. Paradoxalmente, essas características passaram a constituir sua principal limitação. Segundo Santos (1988, p.64) "é hoje reconhecido que a excessiva parcelização e disciplinarização do saber científico faz do cientista um ignorante especializado e (que) isso acarreta efeitos negativos".

Por essas razões sugerimos a realização do trabalho em grupos com uma composição interdisciplinar de profissionais da saúde, considerando que a apresentação e o intercâmbio entre os diferentes vértices poderia revelar de forma mais ampla e multifacetada a complexa realidade de seus pacientes e de suas relações com eles.

Assim como a distinção epistemológica entre sujeito e objeto teve de se colocar em outros termos na psicanálise atual, também a teoria do conhecimento emergente passou a se articular de forma diferente. A fragmentação deixou de ser disciplinar para se tornar temática
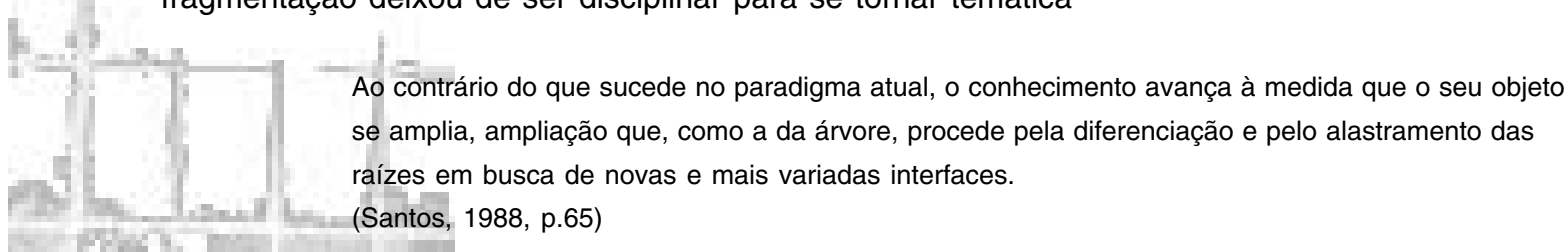

Trabalhar a interdisciplinaridade não significa negar as especialidades e a objetividade de cada ciência. A necessidade de romper com a tendência fragmentadora e desarticulada do processo de conhecimento justifica-se pela compreensão da importância da interação e transformação recíprocas entre as diferentes áreas do saber. Seu sentido reside na oposição à concepção de que o conhecimento se processe em campos fechados em si mesmos, isolados de processos e contextos histórico-culturais, como se as teorias possam ser construídas em mundos particulares sem uma posição unificadora que sirva de fundamento para todas as ciências.

Acreditamos que a introdução de alguns conhecimentos psicanalíticos básicos, articulados com a prática clínica específica de cada área, crie um clima favorável à transmissão e ampliação dos recursos de apreensão psíquica desses profissionais, o que, por sua vez, repercute na percepção dos aspectos subjetivos de seus pacientes.

Nesse sentido, os coordenadores exercem a função que Pichon-Rivière (1983, p.92) chama de "copensor", "aquele que pensa junto com o grupo e ao mesmo tempo reúne e integra os elementos do pensamento grupal”. O ensinar e o aprender formam, então, uma unidade.

\section{Condições e desenvolvimento da experiência}

Tendo em vista os tópicos acima descritos, propusemos à Comissão de Divulgação e Cursos da Sociedade Brasileira de Psicanálise de São Paulo (SBPSP) a realização de seminários semanais de duas horas em grupos de composição interdisciplinar, formados por profissionais da área da saúde, sob a coordenação de duas psicanalistas. Os temas focalizaram basicamente a entrevista, o atendimento, o paciente, o profissional, a relação paciente- profissional, a subjetividade e seu desenvolvimento. O local de realização foi a própria sede da SBPSP e a duração, quatro meses, sendo que os grupos tinham no máximo quinze integrantes. A experiência consta da formação e realização de cinco grupos.

Nosso objetivo não foi apenas o de informação teórica, mas enfatizar que nas discussões fossem incluídos materiais clínicos de experiências de atendimento de cada um, o que permitiria, além do entrelaçamento com a prática, a troca interprofissional. 
Cada integrante expunha uma situação clínica, criando um espaço no qual ia se chegando, por meio de um desenvolvimento progressivo das diversas abordagens, a um saber compartilhado. A comunicação se dava em paralelo à aprendizagem e aos assinalamentos dos mecanismos e afetos envolvidos nesse processo.

Em relação à composição dos grupos, podemos destacar algumas características: quanto à profissão, concentravam-se nas áreas de administração (em setor hospitalar), assistência social, educação física, enfermagem, fisioterapia, fonoaudiologia, magistério, nutrição, pedagogia, psicologia e odontologia; da área médica tivemos representantes da foniatria, pediatria e medicina de urgência; a maioria pertencia ao sexo feminino; a média da faixa etária era de quarenta anos; o tempo médio de experiência profissional situou-se em torno de quinze anos; a maioria tinha experiência em trabalho institucional, seja passada ou presente.

A proposta principal foi o de discutir e trocar experiências sobre questões da relação profissionalpaciente, enfatizando o papel da subjetividade em diferentes situações. A aprendizagem básica deu-se a partir da vivência dos profissionais no próprio grupo, numa atmosfera livre, na qual cada um pôde apresentar suas questões, com a expectativa de iluminá-las graças às experiências dos demais, sentindo-se compreendidos e acolhidos em suas ansiedades. Exceto na seleção dos textos a serem discutidos, a participação das duas psicanalistas no grupo deu-se em igualdade de condições com os demais, apenas salientando nos debates, aspectos do universo "psi" que julgamos relevantes.

Com o propósito de identificar e lidar com manifestações inconscientes presentes nos relacionamentos com os pacientes, procurou-se distinguir a demanda explícita, da fantasia que o paciente trazia sobre a doença. Levávamos em consideração aspectos da dinâmica familiar, sabendo que em grupos familiares, às vezes, a pessoa trazida para tratamento não é a mais necessitada. Enfatizávamos a importância do comportamento não verbal e o das contradições, lacunas, simulações, inibições, silêncios e bloqueios no discurso como dados reveladores dos aspectos inconscientes.

A partir daí discutia-se o significado do sintoma, procurando-se pensar no paciente como um todo. Era observada a necessidade de se procurar entender concomitantemente o que representava aquela angústia para aquele paciente em particular, qual sua função, tanto na própria subjetividade, quanto nas relações intersubjetivas.

Em relação a este tema, puderam ser salientados os aspectos de envolvimento emocional dos profissionais (de sua contra-transferência) que, se de um lado, suscitavam uma posição empática para com o paciente, por outro, poderiam levar a uma total identificação e conseqüente paralisia em seu trabalho.

A partir de casos relatados, muitas vezes evidenciaram-se as expectativas que os pacientes trazem para com o profissional e que, muito freqüentemente, se assemelhavam aos primeiros cuidados que uma criança espera da figura materna e, como conseqüência, uma demanda exacerbada que dificilmente se poderia satisfazer.

A diferença essencial existente entre o profissional que atende na instituição e o que atende em seu consultório também foi abordada, mostrando que, enquanto este último se sentia muitas vezes mais inseguro quanto à aceitação de sua pessoa pelo paciente, o profissional que atende em instituição tem esta por respaldo. Comentou-se, por outro lado, a impessoalidade que é muito freqüente no atendimento institucional.

Paralelamente, evidenciou-se, por exemplos práticos freqüentemente vividos por elementos do grupo, a necessidade de estabelecer limites para determinados pacientes. Nessa ocasião pôde-se discutir o papel do "enquadre" como moldura ou esquema referencial, tanto para o terapeuta quanto para o paciente.

\section{Metodologia}

Destacamos alguns aspectos que puseram em prática as opções de nosso projeto:

Forma grupal - o grupo funcionando como sustentação, não apenas no sentido de acolher as angústias, como também por poder expor o não saber de seus integrantes, cria uma identidade em que se compartilham as experiências e os diferentes papéis. Na medida em que um profissional tem a 


\section{ESPAÇO ABERTO}

possibilidade de ser acolhido pelo grupo, pode também, por sua vez, tornar-se continente dos aspectos emocionais de seus pacientes. Embora tivéssemos a intenção de centralizar as discussões na relação profissional-paciente por meio de relatos que enfatizassem as reações emocionais de ambos nesse contato, tivemos presente a preocupação de impedir desvios que pudessem derivar para um caráter terapêutico do grupo.

Forma das reuniões - De acordo com o tema proposto usamos recursos que possibilitaram discussões e maior aprofundamento. Algumas vezes foram realizados debate de filmes ou leitura de textos não programados anteriormente ou ainda a prática de desenho livre. Um aspecto importante observado nas reuniões referia-se a momentos em que as coordenadoras não sabiam responder de imediato a alguma questão levantada. Desta forma pudemos instrumentalizar o grupo para, diante do não saber, poder tolerar a angústia e a ansiedade disparadas pela perda do já conhecido. A partir da leitura de textos, os diálogos surgiam como um campo no qual se aprendia a observar, ouvir o outro, relacionar as próprias opiniões com as alheias, admitir modos diferentes de pensamento, formular hipóteses resultantes do trabalho de equipe e construir um saber conjunto.

Intersubjetividade - A apreciação da oportunidade de sensibilização dos integrantes do grupo para a intersubjetividade no atendimento de seus clientes foi positiva e a riqueza de experiências obtida mediante a interação e comparação entre as diferentes áreas profissionais foi unânime. Em todos os grupos as avaliações foram semelhantes em valorizar positivamente a multiplicidade de informações obtida por meio da comparação entre as diferentes áreas profissionais. Nesse sentido, outro aspecto significativo foi a interdisciplinaridade.

Uma situação clínica que ilustra essa forma de discutir os casos apresentados deu-se quando uma enfermeira do setor de pediatria de um hospital relatou um caso que chocou a todos os profissionais na época. Era uma menina que fora internada com um quadro agudo de verminose. Chamava a atenção o comportamento dos pais da menina, que nunca tinham feito nenhuma pergunta nem aos médicos, nem ao pessoal da enfermagem. Certa manhã o pai se aproxima da enfermeira e pede autorização para levar a filha à lanchonete do hospital. A profissional autoriza....e a família abandona o hospital.

São despertadas diferentes reações nos profissionais em relação à situação como um todo: a enfermeira que relata o caso sente-se impotente e traída diante dessa conduta; a psicanalista levanta questões no sentido de buscar um entendimento do universo simbólico dessa família. Que angústias a nova situação despertava? Que fantasias cercavam os pais levando-os a desconfiar do tratamento? A assistente social simplesmente identifica: é um comportamento típico de "morador de rua", o que é confirmado pela enfermeira.

São três abordagens diferentes que se complementam e dão um entendimento mais abrangente do episódio apresentado: realizada a discussão, os integrantes do grupo puderam se sensibilizar para interpretações diversas de sua área de trabalho e todos, a partir de sua perspectiva, conseguiram compartilhá-las e construir uma compreensão integrada.

A partir de experiências como essa concordamos com Santos (1988), para quem o conhecimento, que se constitui por uma pluralidade de vértices, evidencia que "cada método é uma linguagem e a realidade responde na língua em que é perguntada. Só uma constelação de métodos pode captar o silêncio que persiste entre cada língua que pergunta" (p.66).

\section{Considerações a partir da experiência}

Podemos destacar alguns dados extraídos da observação da nossa prática:

- A atitude do paciente na relação com o profissional no consultório difere significativamente da mesma atitude na instituição. Há especificidades que envolvem questões relacionadas a pagamento, impessoalidade, responsabilidade, confiabilidade etc. que apareceram em algumas reuniões e mereceram discussões e bibliografia específicas.

- A diferença de idade no grupo não interfere na dinâmica de relacionamento dos participantes. 
- O fato de o profissional estar fora do espaço da instituição em que trabalha parece facilitar a liberdade de expressão e aumentar a confiança no grupo.

- A liberdade dos coordenadores influencia diretamente a forma de participação igualmente mais livre dos outros integrantes.

- O comportamento competitivo só aparece entre profissionais da mesma área.

- Apesar de ter uma percepção adequada, o profissional não se vê com instrumental suficiente para o manejo de algumas situações.

- À medida que os encontros vão acontecendo, vai se estabelecendo uma linguagem comum que se desenvolve na própria comunicação do grupo e, nesse sentido, passa a constituir um patrimônio do grupo.

- Os conceitos de transferência e contra-transferência são os que causam maior interesse nos grupos.

\section{Conclusão}

Entendemos que a psicanálise é uma área do conhecimento que traz uma nova compreensão do ser humano, quando a determinação dos aspectos inconscientes passa a ser levada em consideração.

É fundamental escutar o paciente. Trata-se de trazer o interesse para a personalidade total do paciente, isto é, poder se colocar no lugar do outro e, nesse sentido, compartilhar seus sentimentos, pensamentos e esperanças.

Se um profissional trata como cuidador/curador seu paciente, este leva juntamente com a cura, o registro de uma experiência de ter sido cuidado. O corpo físico pode registrar a cura, mas é a pessoa enquanto ser total que experimenta o vínculo, situação inteiramente diferente de uma condição circunscrita à "erradicação do mal".

Aceitar que as relações entre pacientes e profissionais possam também ser afetadas (de ambos os lados) por sentimentos de amor e ódio e considerá-los como sentimentos fundamentais em todas as relações humanas, implica admitir um conceito que ocupa um lugar importante na psicanálise, que é o conceito de transferência, isto é, a vivência de fortes sentimentos deslocados para o outro no relacionamento. São elementos reprimidos infantis, que ganham nova expressão no espaço emocional, criado pelo encontro "profissional - paciente", sem que este tenha consciência do fenômeno em questão. Numa direção paralela, temos os sentimentos despertados no profissional pelo paciente, que Freud denominou contra-transferência.

Enfatizamos a importância do vínculo afetivo na percepção do outro. Quando admito que o outro está doente, isto

me leva naturalmente para a posição daquele que responde à necessidade, ou seja, à adaptação, à preocupação e à confiabilidade, à cura no sentido de cuidado. Quando falamos de cuidado, estamos falando de amor, mas de um amor que tem que ser fornecido por profissionais.

(Winnicott, 1966, p.90)

\section{Referências}

BENJAMIN, J. Recognition and destruction: an outline of intersubjectivity. In: MITCHELL S., ARON (Orgs.). Relational psychoanalysis. U.S.A.: The Analytic Press, 1990. p.181-210.

BLEGER, J. Grupos operativos en la enseñanza: temas de psicologia (entrevista y grupos). Buenos Aires: Nueva Visión, 1972.

BOFF, L. Saber cuidar: ética do humano, compaixão pela terra. Rio de Janeiro: Vozes, 1999.

PICHON-RIVIÈRE, E. O processo grupal. In: PICHON-RIVIĖRE, E. (Org.) Técnica dos grupos operativos. 1.ed. São Paulo: Martins Fontes, 1983. p.87-98. 


\section{ESPAÇO ABERTO}

SANTOS, B. S. Um discurso sobre as ciências na transição para uma ciência pós-moderna. Estudos Avançados, v.2, n.2, p.48-71, 1988.

WINNICOTT, D.W. A cura (1970): tudo começa em casa. 2.ed. São Paulo: Martins Fontes, 1996.

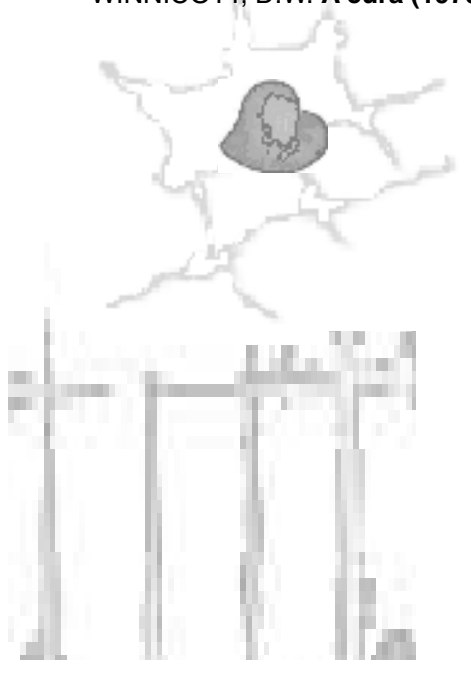

This paper describes an accomplishing experiment by five groups of interdisciplinary reflection, formed by health professionals, under the coordination of two psychoanalysts. The themes discussed are basically centered on the patient-professional relationship, placing emphasis on subjective aspects. The discussions, most of the time, were a reflection on clinical situations governed by theoretical conceptions. The link of the health professional with their patients, considered to be an important therapeutic element, to the extent that it involves elements of affection, was the subject of a psychoanalytical study that brings its specific contribution to the understanding of intersubjectivity. The variety of different professional categories guided the choice of participants and revealed itself to be an important change factor and mutual recognition, thereby providing evidence of the need for dialogue with different forms of human knowledge. The group meetings, besides favoring the exchange of different approaches, allowed for the identification of many aspects in common, as well as providing an atmosphere of welcome, where the professionals could expose their difficulties while at the same time feel themselves supported.

KEY WORDS: Professional-patient relations; care; interdisciplinarity; intersubjectivity; psychoanalytic therapy.

Descreve-se a experiência de cinco grupos de reflexão interdisciplinar de profissionais da saúde sob a coordenação de duas psicanalistas. Os temas discutidos centralizaram-se basicamente sobre a relação paciente - profissional, com ênfase nos seus aspectos subjetivos. As discussões se deram, sobretudo, sobre a reflexão de situações clínicas intermediadas por concepções teóricas. O vínculo do profissional da saúde com seus pacientes, considerado um importante elemento terapêutico, na medida em que envolve conteúdos afetivos, foi objeto de um olhar psicanalítico, trazendo sua contribuição específica na compreensão da intersubjetividade. A variedade das diferentes categorias profissionais norteou a escolha dos participantes e revelou-se um importante fator de troca e mútuo reconhecimento, evidenciando a necessidade de interlocução com formas diversas de conhecimento do humano. A constituição grupal das reuniões, além de favorecer o intercâmbio das diferentes abordagens, possibilitou a identificação de muitos aspectos em comum, assim como propiciou um clima de acolhimento, no qual os profissionais puderam expor suas dificuldades e sentir-se cuidados.

PALAVRAS-CHAVE: Relações profissional-paciente; cuidado; interdisciplinaridade; intersubjetividade; terapia psicanalítica.

Este trabajo describe una experiencia con cinco grupos de reflexión interdisciplinaria, integrados por profesionales del área de salud, coordinados por dos psicoanalistas. Los temas tratados versaron sobre la relación paciente-profesional, subrayando sus aspectos subjetivos. Las discusiones, en su mayoría, son reflexiones sobre situaciones de la clínica intermediadas por concepciones teóricas. El vínculo del profesional de salud con sus pacientes es considerado un importante elemento terapéutico, ya que involucra contenidos afectivos, luego fue objeto de una observación psicoanalítica, la cual pudo aportar una contribución especifica a la comprensión de la intersubjectividad. La variedad de las diferentes categorías profesionales determinó la elección de los integrantes y se reveló un importante factor de intercambio y reconocimiento mutuo, subrayando la necesidad de interlocución con las diversas formas del conocimiento humano. La constitución grupal de las reuniones, además de favorecer el intercambio de los diferentes aportes, posibilitó la identificación de muchos aspectos en común, así como propició un clima acogedor, en el cual los profesionales pudieron exponer sus dificultades y sentirse cuidados.

PALABRAS CLAVE: Relaciones paciente-profesional; cuidado; interdisciplinariedad; intersubjetividad; terapia psicoanalítica. 